\title{
Optimization of Laser-Irradiating Conditions for Vertical Welding on Thick Steel Plate using Hot-Wire Laser-Welding Method*
}

\author{
by SITTISAK Charunetratsamee ${ }^{* *}$, EAKKACHAI Warinsiriruk ${ }^{* * *}$, SHINOZAKI Kenji ${ }^{* * * *}$ and YAMAMOTO Motomichi ${ }^{* *}$ \\ We investigated the effect of laser-irradiating conditions—-specifically laser spot size, laser power density and laser weaving. Three laser \\ spot widths of 10, 4 and $2 \mathrm{~mm}$ were applied by changing the optical-lens and fiber-cable combination to investigate the effects of the laser power \\ density and laser spot width. The weaving-irradiating method was applied with narrow laser widths of 4 and $2 \mathrm{~mm}$. The effects of the laser- \\ irradiating condition were obtained based on high-speed imaging during welding and cross-sectional observation. Stable laser irradiation by a \\ $10-\mathrm{mm}$ laser spot width provided a lower power density than the critical value of $35 \mathrm{~W} / \mathrm{mm}^{2}$ and a lack of fusion. Weaving laser irradiation by a \\ 4- or 2-mm laser spot width provided a higher power density, reduced the large lack of fusion and achieved a large penetration of base metal. The \\ ratio between the laser beam-spot width and gap width $\left(\mathrm{W}_{\mathrm{L}} / \mathrm{W}_{\mathrm{G}}\right.$ ratio) affect the base-metal fusion significantly. A sound $\mathrm{W}_{\mathrm{L}} / \mathrm{W}_{\mathrm{G}}$ ratio promoted \\ base-metal fusion by providing a uniform and stable molten-pool temperature, whereas a small $\mathrm{W}_{\mathrm{L}} / \mathrm{W}_{\mathrm{G}}$ ratio maintained a smaller fusion area \\ because of the sudden temperature drop and temperature fluctuation of the molten pool.
}

Key Words: Hot-wire, Laser welding, Diode laser, Single-pass vertical welding, Thick steel plate, Laser-irradiating condition

\section{Introduction}

In recent years, super-large ships with capacities of over 20,000 TEU (20-foot equivalent units) have been built and operated. Larger container ships require the use of heavy-thick steel plates with a higher strength and toughness, especially for hatch-side coaming structures, owing to the open upper-deck structure of such ships ${ }^{1-3)}$. Although electrogas arc welding is usually used on vertical butt joints of heavy-thick steel plates in the ship-building industry because of its high productivity with a single-pass, its high-heat input reduces the toughness and induces softening of the welded joint ${ }^{2-8)}$. Thus, there is a strong demand for a new vertical welding process that can reduce the heat input and join the butt joint of heavy-thick steel plates with a single-pass to achieve a high strength and toughness of the welded joint

A novel vertical welding process for thick steel plates that uses a hot-wire laser welding method ${ }^{9-11)}$ has been proposed and investigated previously ${ }^{12-13)}$. In a preliminary investigation of the proposed process ${ }^{12}$, single-pass vertical welding for 26-mm-thick steel-plate joints has been achieved using a diode laser as a main heat source combined with double hot-wire feeding. A rectangular laser spot with a long and narrow shape that fits the plate thickness and groove width have allowed for the stable formation of a large molten pool during single-pass vertical welding. The laser power density has been the main parameter to obtain a sound bead without a lack of fusion, and a critical power density has been

\footnotetext{
*受付日 令和元年 8 月 27 日 受理日 令和元年 9 月 10 日

**学生員 広島大学大学院工学研究科 Student member, Graduate School of Engineering, Hiroshima University

*** ママヒドン大学 Faculty of Engineering, Mahidol University

****正 員 点工業高等専門学校 Member, National Institute of Technology, Kure College

*****正員広島大学大学院工学研究科 Member, Graduate School of Engineering, Hiroshima University
}

needed for adequate fusion of a base metal depending on the welding speed. The effects of laser-irradiating angle and single hot-wire feeding on the molten pool and joint formations have been investigated previously ${ }^{13}$. Better molten-pool formation and base-metal melting have been obtained using $15^{\circ}$ oblique laser irradiation with single hot-wire feeding.

The objective of this study was to investigate the laser-irradiating conditions of a laser spot size, laser power density and laser spot weaving on molten-pool formation and weld-bead creation. Three laser spot sizes of $10 \mathrm{~mm} \times 26 \mathrm{~mm}, 4 \mathrm{~mm} \times 27 \mathrm{~mm}$ and $2 \mathrm{~mm} \times$ $27 \mathrm{~mm}$ were applied by changing the optical-lens and fiber-cable combination to investigate the effects of the laser power density and laser spot width. The weaving-irradiating method was also applied with a narrow laser spot of $4 \mathrm{~mm} \times 27 \mathrm{~mm}$ and $2 \mathrm{~mm} \times$ $27 \mathrm{~mm}$. The effects of laser-irradiating condition were obtained based on high-speed imaging during welding and cross-sectional observation.

\section{Experimental procedure}

\subsection{Materials and specimen}

KE47-class steel plates and a JIS Z 3325 YGL2-6A (AP) filler wire of 1.6-mm diameter and 50-mm width, 200-mm height $X$ 26-mm thickness were used as shown in Fig. 1. The groove width (gap) was set to $10 \mathrm{~mm}$ by using a bottom spacer with a $10-\mathrm{mm}$ width, 20-mm height and 26-mm depth.

\subsection{Experimental setup and welding conditions}

The joint-configuration layout and apparatus for stationary laser irradiation and weaving laser irradiation is presented schematically in Fig. 2. Table 1 gives the welding conditions used. Oblique laser irradiation with single hot-wire feeding that had been investigated previously was used. A laser irradiating angle of $15^{\circ}$ and a welding 
speed of $3.33 \mathrm{~cm} / \mathrm{min}$ were fixed in all experiments.

A $6-\mathrm{kW}$ diode laser oscillator was used as a heat source with combined focusing and homogenizing lenses providing a long and narrow rectangular shape for the laser spot. Three leaser spot widths were used by changing the combination of a focusing lens, homogenizing lens and optical fiber diameter to investigate the effect of a laser power density on the welding phenomena. These combinations fit the laser spot length to the groove length (plate thickness). Figure 3 shows a schematic of the laser-beam-irradiating conditions with three laser spot widths in the groove during weaving.

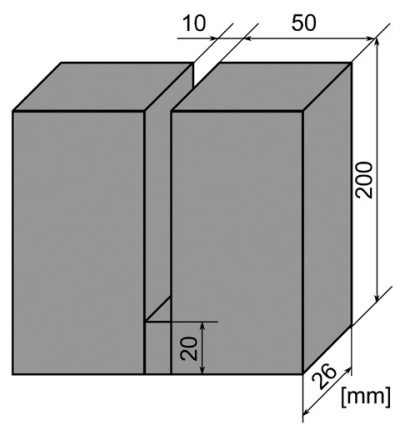

Fig.1 Specimen dimensions in hot-wire laser welding.

Table 1 Welding conditions

\begin{tabular}{|c|c|c|c|}
\hline Laser irradiation method & Stationary & \multicolumn{2}{|c|}{ Weaving } \\
\hline Weaving frequency, $\mathrm{Hz}$ & & \multicolumn{2}{|c|}{5} \\
\hline Weaving waveform & & \multicolumn{3}{|c|}{ Exponential } \\
\hline Laser irradiating angle, deg. & \multicolumn{3}{|c|}{15} \\
\hline Laser power, $\mathrm{kW}$ & \multicolumn{3}{|c|}{6} \\
\hline Spot size (Just focus), $\mathrm{mm}$ & $10^{\mathrm{w}} \times 26^{1}$ & $4^{\mathrm{w}} \times 26^{1}$ & $1.6^{\mathrm{w}} \times 26^{1}$ \\
\hline Spot size (Defocus), mm & & $4^{\mathrm{w}} \times 27^{1}$ & $2^{\mathrm{w}} \times 27^{1}$ \\
\hline Defocus amount, $\mathrm{mm}$ & 0 & 20 & 20 \\
\hline Laser power density, $\mathrm{W} / \mathrm{mm}^{2}$ & 23 & 55 & 111 \\
\hline Welding speed, $\mathrm{cm} / \mathrm{min}$ & \multicolumn{4}{|c}{3.3} \\
\hline Wire feeding speed, $\mathrm{m} / \mathrm{min}$ & \multicolumn{5}{|c}{5.31} \\
\hline Wire current, $\mathrm{A}$ & 161 & 181 & 164 \\
\hline Wire feeding angle, deg. & \multicolumn{5}{|c}{5} \\
\hline Wire feeding position, $\mathrm{mm}$ & \multicolumn{5}{|c}{10} \\
\hline Shielding gas (Ar), $1 / \mathrm{min}$ & \multicolumn{3}{|c}{} \\
\hline
\end{tabular}

The widest laser spot width of $10 \mathrm{~mm}$ with the lowest laser power density of $23 \mathrm{~W} / \mathrm{mm}^{2}$ was used for stationary laser irradiation to fit the groove width (gap). Narrower laser spot widths of 4 and $2 \mathrm{~mm}$ with the middle and highest laser power densities of 55 and $111 \mathrm{~W} / \mathrm{mm}^{2}$ used with a laser weaving system. The ratio between

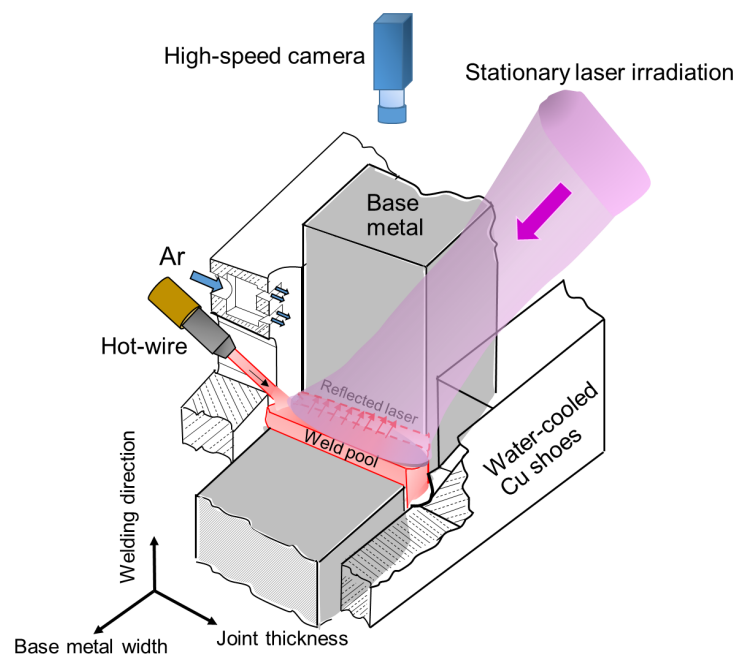

(a) Stationary laser irradiation

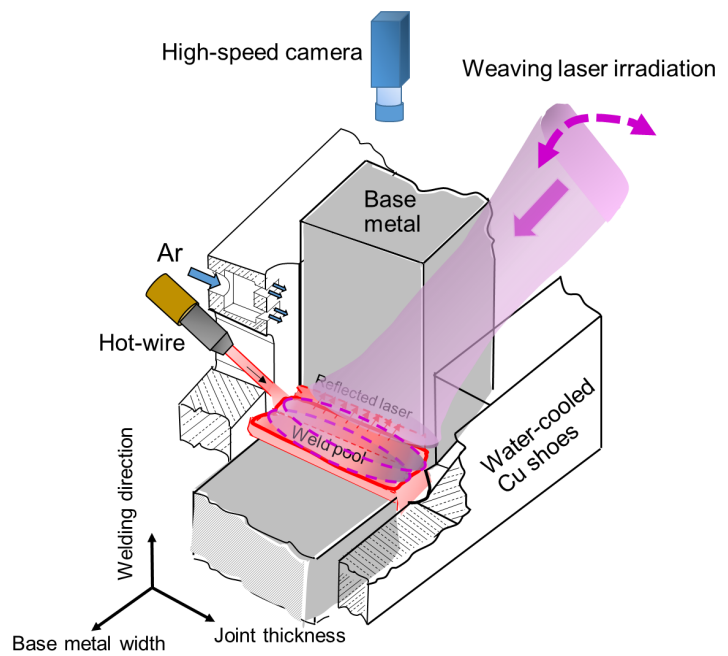

(b) Weaving laser irradiation.

Fig. 2 Schematic layout of joint configuration and apparatus.

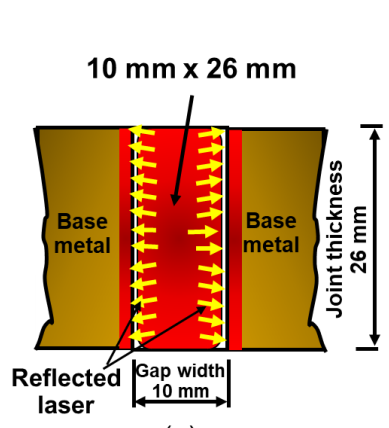

(a)

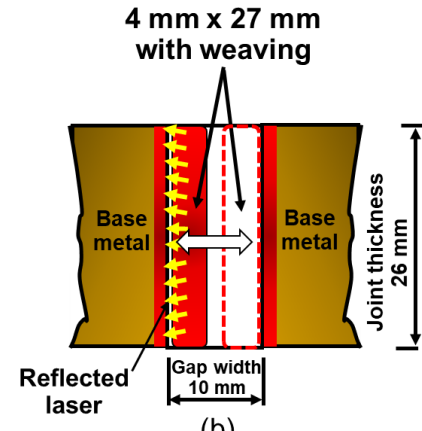

(b)

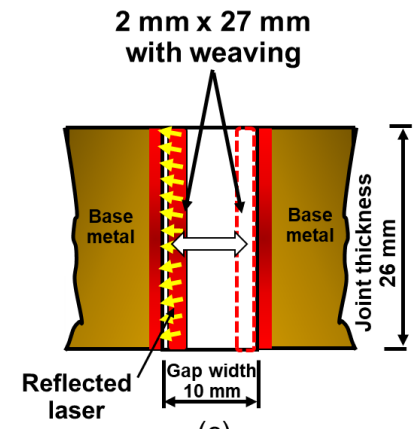

(c)

Fig.3 Schematics of laser-beam shapes and laser-weaving conditions. 
the laser beam spot width $\left(\mathrm{W}_{\mathrm{L}}\right)$ and gap width $\left(\mathrm{W}_{\mathrm{G}}\right)$, or the $\mathrm{W}_{\mathrm{L}} / \mathrm{W}_{\mathrm{G}}$ ratio, was defined as a key parameter. The $\mathrm{W}_{\mathrm{L}} / \mathrm{W}_{\mathrm{G}}$ ratio is $1.0,0.4$ and 0.2 for the $10-\mathrm{mm}, 4-\mathrm{mm}$ and 2-mm laser-beam spot width.

The weaving system can sweep the large rectangular laser spot parallel to the gap width. The weaving amplitude can be adjusted to a variable gap and the weaving frequency can also be changed. The weaving amplitude was defined to fit the 10-mm gap, and a $5-\mathrm{Hz}$ weaving frequency was used. Figure 4 shows a schematic of the laser-beam spot motion and the weaving amplitude during one weaving cycle. The holding time of the laser spot near the groove surface was $\sim 72.5 \mathrm{~ms}$ and the time taken to move through the opposite groove surface was only $\sim 27.5 \mathrm{~ms}$ for the conditions in Table 1 .

The hot-wire feeding speed was adjusted to fill the groove, and the wire current was set to heat the filler wire tip to near its melting point appropriately in consideration of a heat input from direct laser irradiation under several laser power densities. Argon gas was used for shielding.

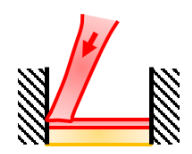

$72.5 \mathrm{msec}$

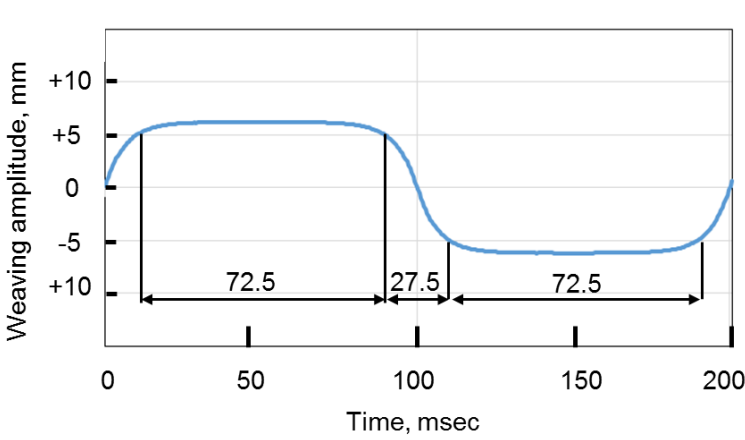

Fig. 4 Schematic of laser-spot motion and weaving amplitude.

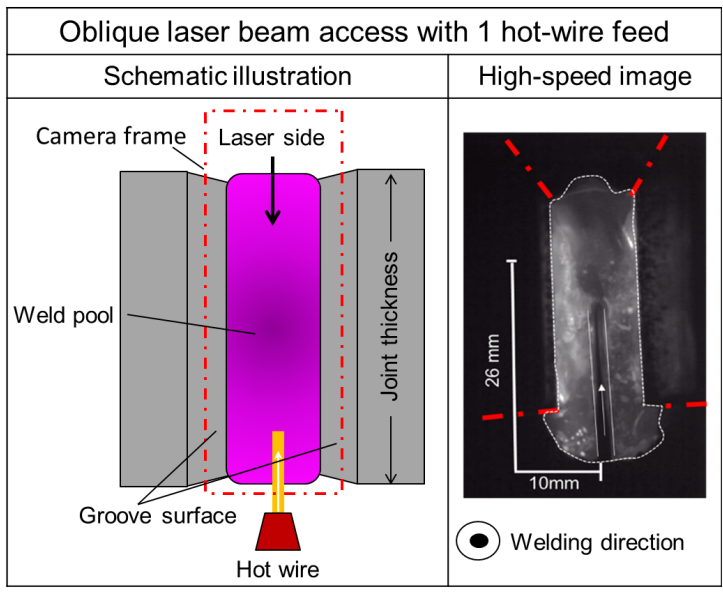

Fig.5 Schematic and captured image of molten pool and hot wire during welding.
A high-speed camera was used to observe the molten-pool formation and stability, and the feeding of the hot wire during welding. An image of the molten pool and hot wire was captured from the upper side of the groove as shown in Fig. 2. Figure 5 shows a schematic and captured image of a molten pool and hot wire during welding. The shooting conditions of a frame rate of $50 \mathrm{fps}$ and a shutter speed of $1 / 20000 \mathrm{~s}$ were used with an $810-\mathrm{nm}$ band-pass filter. The image that was captured during welding can be used to observe molten-pool formation and hot-wire feeding, and to investigate qualitatively the temperature distribution on a molten pool.

\section{Results and discussion}

\subsection{Molten-pool formation during welding}

Figure 6 shows high-speed images of a molten pool and a hot wire during welding for three laser-irradiating conditions at 50and $70-\mathrm{mm}$ locations in the welding direction from the welding starting point. The molten pool is indicated as a white dashed line, hot-wire feeding into the molten pool is indicated as a white solid line and arrow, and the groove (base metal) edge is shown as a red chain line. The high-speed images show the stable molten pool formation and hot-wire feeding in both locations under all laserirradiating conditions.

All images show that while a molten pool grew sufficiently at the filler wire feeding side (lower side in Fig. 6), it grew inadequately at the laser-irradiating side (upper side in Fig. 6) in the groove This molten-pool formation would be caused by oblique laser irradiation that was used. This irradiating condition provided

\begin{tabular}{|c|c|c|c|}
\hline & \multicolumn{3}{|c|}{ Laser irradiating method } \\
\hline & Stationary & Weaving 5 & onential wave \\
\hline & \multicolumn{3}{|c|}{ Laser spot size, width $x$ length $(\mathrm{mm} \times \mathrm{mm})$} \\
\hline & $10 \times 26$ & $4 \times 27$ & $2 \times 27$ \\
\hline \multirow{2}{*}{$\begin{array}{l}\text { Observed } \\
\text { position }\end{array}$} & \multicolumn{3}{|c|}{ Power density, $\mathrm{W} / \mathrm{mm}^{2}\left(\mathrm{~W}_{\mathrm{L}} / \mathrm{W}_{\mathrm{G}}\right.$ ratio $)$} \\
\hline & $23(1.0)$ & $55(0.4)$ & $111(0.2)$ \\
\hline \multicolumn{4}{|l|}{$\begin{array}{c}\text { Laser Side } \\
\downarrow\end{array}$} \\
\hline $50 \mathrm{~mm}$ & & & \\
\hline \\
\hline $70 \mathrm{~mm}$ & & & \\
\hline Wire Side & & & \\
\hline
\end{tabular}

Fig. 6 High-speed images during welding for three laser-irradiating conditions at 50- and 70-mm locations in the welding direction from the welding start point. 
efficient laser irradiation and heat input on the filler-wire-feeding side, but insufficient laser irradiation and heat input on the laserirradiating side.

When the stationary laser irradiation with a laser spot of $10 \mathrm{~mm}$ $\times 26 \mathrm{~mm}$, which provided the lowest laser power density of $23 \mathrm{~W} / \mathrm{mm}^{2}$, was used, insufficient growth of the molten pool at the laser-irradiating side was more visible compared with that of the laser-weaving conditions with narrower laser spots. This result implies a low wetting condition near the groove surfaces because of a low heat input and a small amount of base-metal melting under this condition. When the laser-weaving method with a laser spot of $4 \mathrm{~mm} \times 27 \mathrm{~mm}$ or $2 \mathrm{~mm} \times 27 \mathrm{~mm}$, which provided a higher laser power density of 55 or $111 \mathrm{~W} / \mathrm{mm}^{2}$, was used, the molten pool at the laser-irradiating side in the groove grew better compared with that in the stationary laser-irradiating condition. The higher power density with laser-weaving irradiation may have created a better wetting condition near the groove surfaces at the laser-irradiating side because of the higher heat input and larger amount of base-metal melting.

\subsection{Molten-pool temperature distribution during welding}

Figure 7 shows the contour image of the relative radiative intensity on a molten-pool surface transformed from the high-speed image in Fig. 6. The grayscale image that was captured thorough the 810$\mathrm{nm}$ band-pass filter with an 8-bit color depth was converted to a

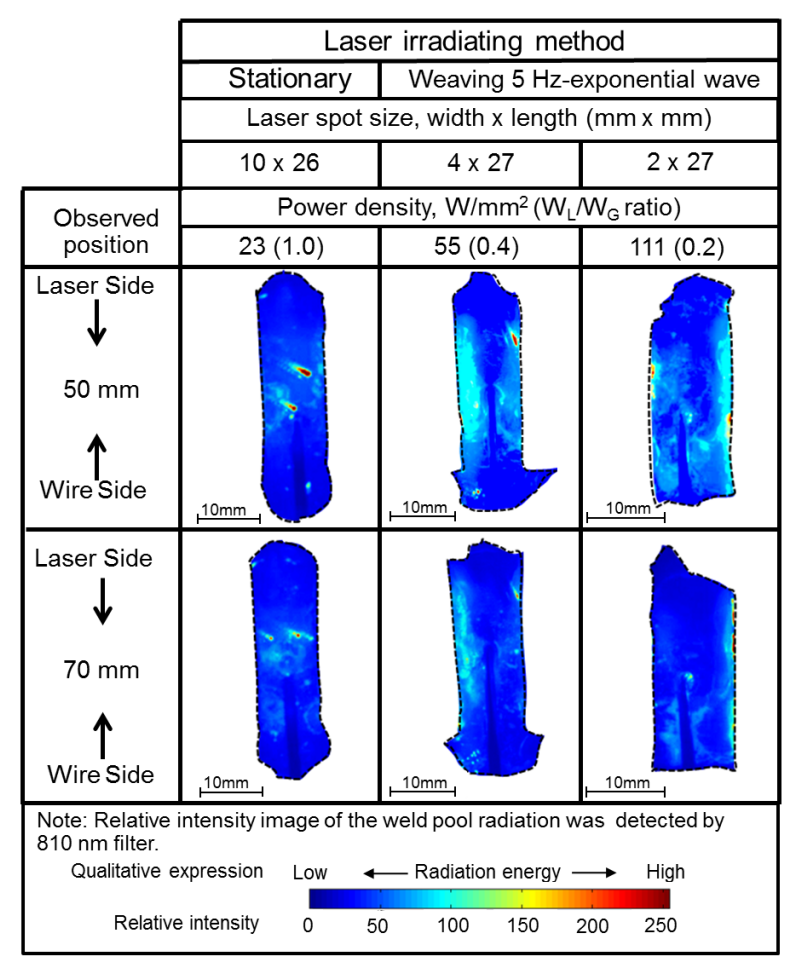

Fig. 7 Intensity distribution on molten-pool surface by high-speed image captured during welding at 50 - and $70-\mathrm{mm}$ locations in the welding direction from the welding start point. color relative-intensity image. The small relative intensity in blue means a lower temperature on the molten pool because of the low heat input from laser irradiation. The large relative intensity in red means a higher temperature because of the high heat input from laser irradiation.

For all laser-irradiation conditions, the intensity at the edge regions of the laser and wire sides on the molten pool is lower than that at the center. Therefore, the lower temperature at the edge regions on the molten pool induces a high probability of a lack of fusion compared with the center region. A higher intensity near both grooves (base metal) was observed when weaving irradiation was applied with a narrow 2- and 4-mm laser-spot width compared with stationary irradiation without weaving by using the wider laser-spot width of $10 \mathrm{~mm}$. This high intensity means that a high temperature was created by the higher laser power density of $55 \mathrm{~W} / \mathrm{mm}^{2}$ for the $4-\mathrm{mm}$ width and $111 \mathrm{~W} / \mathrm{mm}^{2}$ for the 2-mm width compared with $23 \mathrm{~W} / \mathrm{mm}^{2}$ for the $10-\mathrm{mm}$ width of the laser spot. The weaving irradiation with an exponential waveform and a long holding time at the groove boundary of $72.5 \mathrm{~ms}$ in the $5-\mathrm{Hz}$ frequency as shown in Fig. 4 created a higher temperature near both grooves (base metal) and encouraged base-metal fusion. Although a high intensity along the groove (base metal) is visible at the laser-irradiating side when the narrowest laser spot width of $2 \mathrm{~mm}$ with the highest power density was applied, the relatively lower intensity is visible at the opposite groove side and center region on the molten pool. It can be presumed that too narrow a laser-spot width, compared with the groove width (gap) does not maintain an adequate molten-pool temperature over the entire area in the gap during weaving because this narrow laser spot provides heat input only in the limited narrow region. Therefore, the temperature near one groove side, where the laser does not irradiate, drops rapidly during laser-spot irradiation at the opposite groove side.

These results imply that a laser power density and relative laser spot width to groove width (gap) of $10 \mathrm{~mm}$, or the $\mathrm{W}_{\mathrm{L}} / \mathrm{W}_{\mathrm{G}}$ ratio, would affect molten-pool formation and base-metal melting during welding.

\subsection{Joint and defect formations}

Figure 8 shows macro-cross-sections of welded joints in the horizontal direction 50- and 70-mm in the welding direction from the welding starting point for three laser-irradiating conditions. Sufficient weld metal at the edge of the wire-feeding side and insufficient weld metal at the edge of the laser-irradiating side result for all three conditions. The oblique laser-irradiating condition could not provide sufficient heat input at the edge on the laser-irradiating side in the groove and could not create sufficient temperature as shown in Figs. 6 and 7. This inadequate temperature condition resulted in insufficient base-metal melting and weld-metal creation 


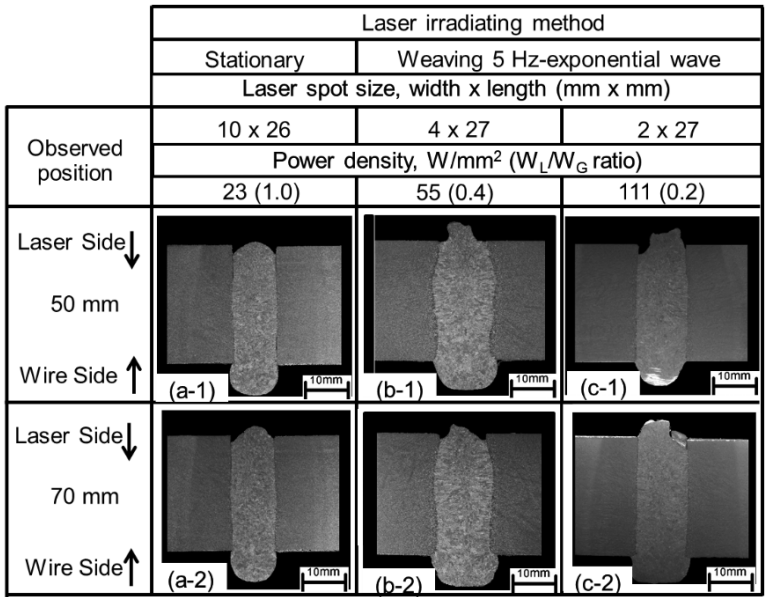

Fig. 8 Horizontal cross-sections of welded specimens at 50- and 70 -mm locations in the welding direction.

in this region.

Figure 9 shows the bead-width distribution and lack of fusion generation in the thickness direction measured using crosssectional images as shown in Fig. 8. The results from the stationary laser-irradiating condition (Fig.9(a)) show that a large lack of fusion (LOF) was generated at the laser-irradiating side and wirefeeding side. The small melting area of the base metal and the maximum penetration depth of $1 \mathrm{~mm}$ resulted under this condition. A small LOF was generated only at the laser-irradiating side and a large melting area was visible as a result of the weaving laserirradiating conditions (Fig. 9(b) and (c)). The lowest power density of $23 \mathrm{~W} / \mathrm{mm}^{2}$ in the stationary laser-irradiating condition using the widest laser spot of $10 \mathrm{~mm} \times 26 \mathrm{~mm}$ did not provide sufficient heat input to the groove surfaces and the temperature was not elevated sufficiently as shown in Fig. 7.

For two weaving laser-irradiating conditions, the lower powerdensity condition of $55 \mathrm{~W} / \mathrm{mm}^{2}$ with the wider laser spot of $4 \mathrm{~mm}$ $\times 27 \mathrm{~mm}$ creates a larger melting area and base-metal penetration compared with those under the higher power-density condition of $111 \mathrm{~W} / \mathrm{mm}^{2}$ using the narrower laser spot of $2 \mathrm{~mm} \times 27 \mathrm{~mm}$. The laser irradiation using the laser power density of $111 \mathrm{~W} / \mathrm{mm}^{2}$ with the spot size of $2 \mathrm{~mm} \times 27 \mathrm{~mm}$ and a $\mathrm{W}_{\mathrm{L}} / \mathrm{W}_{\mathrm{G}}$ ratio of 0.2 yields a stable and consistent small melting depth on the entire length without the edge at the laser-irradiating side. The maximum penetration depth of the laser-irradiating condition is $1.2 \mathrm{~mm}$, which is almost the same as that of the stationary laser-irradiating condition, but the small LOF length of $2 \mathrm{~mm}$ is generated only on the edge at the laser-irradiating side. The laser-irradiating condition using the laser power density of $55 \mathrm{~W} / \mathrm{mm}^{2}$ with a spot size of $4 \mathrm{~mm} \times 27 \mathrm{~mm}$ and $a W_{L} / W_{G}$ of 0.4 yields a larger melting region than that of the aforementioned cases. The maximum penetration was $2 \mathrm{~mm}$, but the LOF still occurred with a length of $2 \mathrm{~mm}$ on the edge at the laser-irradiating side.

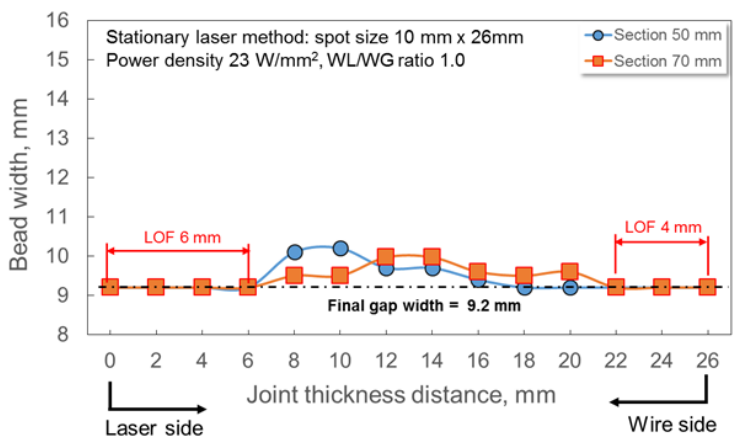

(a) Stationary laser irradiation, spot size: $10 \mathrm{~mm} \times 26 \mathrm{~mm}$

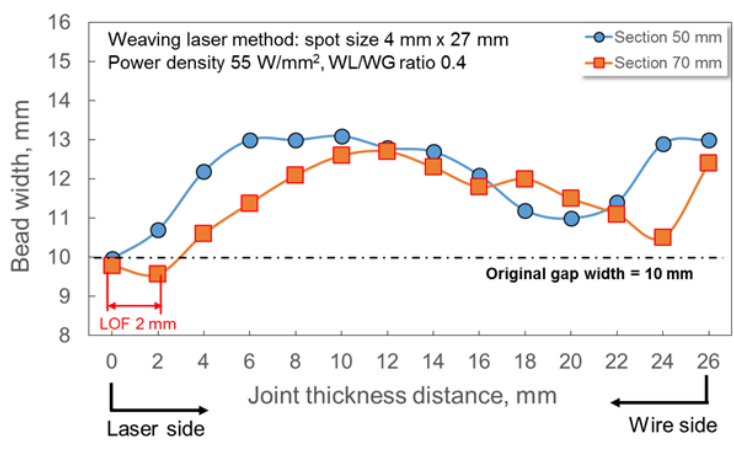

(b) Weaving laser irradiation, spot size: $4 \mathrm{~mm} \times 27 \mathrm{~mm}$

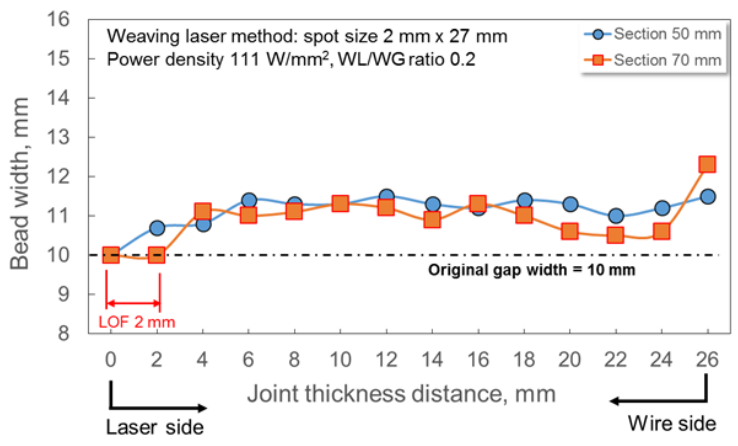

(c) Weaving laser irradiation, spot size: $2 \mathrm{~mm} \times 27 \mathrm{~mm}$

Fig.9 Bead-width distribution and lack of fusion (LOF) generation in thickness direction.

\subsection{Effect of laser-irradiating condition on joint formation}

Figure 10 summarizes the effect of the power density and $\mathrm{W}_{\mathrm{L}} / \mathrm{W}_{\mathrm{G}}$ ratio on the maximum bead width and accumulated imperfection. A previous report ${ }^{12)}$ showed that the critical laser power density to melt the groove surface (base metal) was $35 \mathrm{~W} / \mathrm{mm}^{2}$ for the same welding speed of $3.3 \mathrm{~cm} / \mathrm{min}$ by using the stationary laser irradiation. From the results, it can be presumed that the weaving laser irradiation by using the long-length narrow-width laser beam maintains a higher power density than the critical value for the groove surface (base metal) melting, whereas stationary laser irradiation using a long-length wide-width laser beam does not maintain the power density above the critical value.

The spot size of $2 \mathrm{~mm} \times 27 \mathrm{~mm}$ provided a much higher laser 


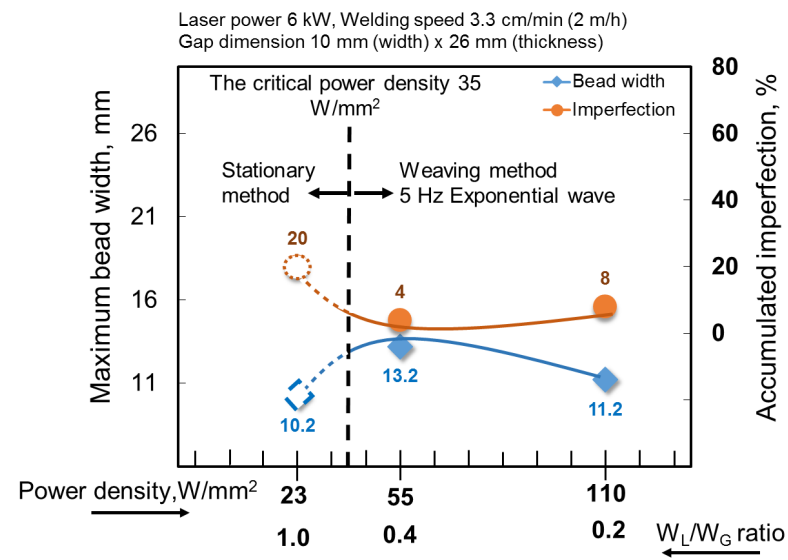

Fig.10 Effects of laser power density and $W_{L} / W_{G}$ ratio on maximum bead width and accumulated imperfection.

power density of $111 \mathrm{~W} / \mathrm{mm}^{2}$ than the critical value of $35 \mathrm{~W} / \mathrm{mm}^{2}$, which achieved stable fusion of the groove surface (base metal), whereas the small $\mathrm{W}_{\mathrm{L}} / \mathrm{W}_{\mathrm{G}}$ ratio of 0.2 did not maintain the moltenpool temperature stable over the entire area and contribute to heatconduction fusion of the groove surface (base metal). Therefore, the laser irradiating condition with the $2 \mathrm{~mm} \times 27-\mathrm{mm}$ spot size created a uniform and small fusion area through the plate thickness. The spot size of $4 \mathrm{~mm} \times 27 \mathrm{~mm}$ provided a higher laser power density of $55 \mathrm{~W} / \mathrm{mm}^{2}$ than the critical value of $35 \mathrm{~W} / \mathrm{mm}^{2}$, and the large $\mathrm{W}_{\mathrm{L}} / \mathrm{W}_{\mathrm{G}}$ ratio of 0.4 kept the molten-pool temperature over the entire area stable to contribute heat-conduction fusion of the groove surface (base metal). As a result, the laser-irradiating condition with the $4 \mathrm{~mm} \times 27-\mathrm{mm}$ spot size produced a large melting area especially on the center region in the thickness direction.

The above result indicates that the laser power density and $\mathrm{W}_{\mathrm{L}} / \mathrm{W}_{\mathrm{G}}$ ratio affect the groove surface melting. A laser power density above the critical value of $35 \mathrm{~W} / \mathrm{mm}^{2}$ is required to achieve stable melting of the groove surface and to avoid defect formation. An adequate $\mathrm{W}_{\mathrm{L}} / \mathrm{W}_{\mathrm{G}}$ ratio, which is 0.4 in this research, contributes to a more efficient and stable creation of groove surface fusion by maintaining a uniform and sufficient molten-pool temperature.

\section{Conclusions}

The effect of laser-irradiating conditions of a laser spot size, laser power density and weaving on molten-pool formation and weld-bead creation were investigated during single-pass hot-wire laser vertical welding for butt joints of thick steel plates. The conclusions are as follows.

(1) The laser spot should have the same long length as the plate thickness and a narrow width compared with the groove width to maintain a high power density, stable molten pool and sound bead formations on the butt joint of the 26-mm-thick steel plate.

(2) Stable laser irradiation without weaving provides a lower laser power density than the critical value of $35 \mathrm{~W} / \mathrm{mm}^{2}$ and produces a large LOF. Weaving laser irradiation provides a higher laser power density than the critical value of $35 \mathrm{~W} / \mathrm{mm}^{2}$, reduces the LOF, and achieves a high base-metal penetration.

(3) The sound $\mathrm{W}_{\mathrm{L}} / \mathrm{W}_{\mathrm{G}}$ ratio, which is 0.4 in this research, achieves the largest base-metal fusion area because it maintains an adequate uniform and stable temperature of the molten pool. The small $\mathrm{W}_{\mathrm{L}} / \mathrm{W}_{\mathrm{G}}$ ratio, which is 0.2 in this research, maintains a smaller fusion area because it produces a sudden temperature drop and temperature fluctuation of the molten pool with laser spot weaving.

\section{Acknowledgements}

This research was supported by The Amada Foundation.

\section{References}

1) S. Okano, Y. Obanya, K. Abe, K. Hosoi: Latest Technical Trends in Steel Plate and Action in Kobe Steel, Kobe Steel Eng. Reports, 58-1 (2008), 2-7.

2) T. Yokura: Practical Lecture - A Class in Joining \& Welding Shipbuilding (Process \& Construction), J. JWS, 81-6 (2012), 43-50.

3) R. Uemori, M. Fujioka, T. Inoue, M. Minagawa, H. Shirahata, T. Nose: Steels for Marine Transportation and Construction, Nippon Steel Technical Report, 391 (2011), 37-47.

4) M. Sato: Lecture for Practical Engineer - Electrogas Arc Welding Process -, J. JWS, 66-4 (1997), 274-278.

5) C.-M. Kim, J.-B. Lee, W.-Y Choo: Characteristics of Single Pass Welds in $50 \mathrm{~kJ} / \mathrm{mm}$ of Heavy Thickness Shipbuilding Steel, Proc. 2003 ISOPE, (2003), 90-96.

6) K. Sasaki, K. Suda, R. Motomatsu, Y. Hashiba, S. Okita, S. Imai: Development of Two-electrode Electro-gas Arc Welding Process, Nippon Steel Technical Report, 380 (2004), 57-63.

7) Y. Funatsu, J. Otani, K. Hirota, T. Matsumoto, H. Yajima: Development of Higher Toughness YP47 $\left(460 \mathrm{~N} / \mathrm{mm}^{2}\right)$ Class Steel Plate for Large Container Ships, Proc. 2010 ISOPE (2010), 102-106.

8) S. Suzuki, K. Ichiyama, T. Akita: High Tensile Strength Steel Plates with Excellent HAZ Toughness for Shipbuilding - JFE EWEL Technology for Excellent Quality in HAZ of High Heat Input Welded Joints -, JFE Technical Report, 5 (2005), 24-29.

9) M. Yamamoto, K. Shinozaki, K. Kadoi, D. Fujita, T. Inoue, M Fukahori, Y. Kitahara: Development of Hot-wire Laser Welding Method for Lap Joint of Steel Sheet with Wide Gap, Quarterly J. JWS, 29-3 (2011), 58-61.

10) K. Kadoi, K. Shinozaki, M. Yamamoto, K. Owaki, K. Inose, D. Takayanagi, Development of high-efficiency and High-quality Hotwire Laser Fillet Welding Process, Quarterly J. JWS, 29-3 (2011), $62-65$.

11) R. Phaonaim, K. Shinozaki, M. Yamamoto, K. Kadoi, S. Tsuchiya, A. Nishijima: Development of a highly efficient hot-wire laser hybrid process for narrow-gap welding - welding phenomena and their adequate conditions, Welding in the World, 57 (2013), 607-613.

12) E. Warinsirirruk, K. Hashida, M. Yamamoto, K. Shinozaki, K. Kadoi, T. Tanino, H. Yajima, T. Fuki, S. Nakayama, T. Nose, S. Tsuchiya, H. Watanabe, T. Kanazawa: Welding Phenomena during Vertical Welding on Thick Steel Plate using Hot-wire Laser Welding Method, Quarterly J. JWS, 33-2 (2015), 143-147.

13) E. Warinsirirruk, K. Hashida, M. Yamamoto, K. Shinozaki, K. Kadoi, H. Yajima, T. Tanino, T. Fuki, S. Nakayama, S. Tsuchiya, H. Watanabe, T. Kanazawa: Oblique laser irradiation technique for vertical welding of thick steel plates employing hot-wire laser welding, Quarterly J. JWS, 33-4 (2015), 326-331. 